\title{
浅谈通过唐诗了解宫女的生活
}

\section{A STUDY OF IMPERIAL MAIDS’ LIFE THROUGH TANG'S POETRY}

\author{
Xuc Lin \\ Chinese Department, Faculty of Humanities, BINUS University, \\ Jln. Kemanggisan Ilir III no 45, Kemanggisan - Palmerah, Jakarta Barat 11480, \\ basenji88@yahoo.com
}

\begin{abstract}
Article observed the life of Tang's imperial maids through the poetry of Tang Dynasty. . Imperial maids were started from Sui Dynasty, especially Emperor Sui Yangdi's period, and Tang's imperial maids were many. Emperor with various kind of reasons, in most every year would choose some girls and took them into his palace and they worked as imperial maids. They were girls from ordinary people, respectable, and noble families. Those girls who once entered imperial palace, theyb would be very hard to come out. They had to obey the regulation in the palace. Through some poetry it could be portrayed the imperial maids' lifetime in serving the emperor, imperial concubines and got rest after midnight. Except for working, they weren't able to come out from palace, they couldn't go home to visit their family, even got married, their lives were full of loneliness. If they were sick, or old, the emperor wouldn't like them anymore, they would be sent away anytime. Even if they left imperial palace, and got their freedom, but most of them lived tragically.
\end{abstract}

Keywords: Tang's poetry, imperial maid, life

\section{摘要}

本论文介绍通过唐诗看唐代宫女的生活。宫女来自隋朝时期尤其是隋炀帝时期, 而唐代宫 女达到很高的数量。皇帝以各种原因每隔几年都会挑选一些女子来进宫当宫女的, 而她们有的 来民间的姑娘, 也有的是大家闺秀, 贵族千金。这些女子一旦进宫了就很难出去, 她们都必须 遵守宫里的制度。通过一些诗歌我们看到宫女一辈子在宫里伺候皇帝、嫔妃们都忙着到深夜才 能休息。除了劳动以外我们也可以看出她们因为无法出宫、探亲甚至嫁人, 生活在宫里是很寂 寞的。如果她们生病、年老了、皇帝不喜欢等因素就随时能被放出宫。即使有些能离开皇宫得 到了她们的自由但是大部分的宫女流落民间后命运很悲惨的。

关键词：唐诗；宫女；生活 


\section{前言}

唐代的妇女作品很多, 题材也很丰富。大部分所谈的女性是宫女、思妇、劳动妇女、 贵族妇女和歌舞伎。宫女是王制、封建制所生产的职业, 只要有君主后妃, 就必然有宫 女。据历史的记载, 唐代后宫非常多, 而如果我们想了解她们的生活、她们的命运, 我 们不仅看历史的记载而是通过唐诗尤其 “宫词” 能让我们更了解她们的生活。唐代存在 的宫词也非常多所以可以给我们提供不少的资料。

皇帝每隔几年都要选大量的年轻又漂亮女子进宫, 其中有民间姑娘, 有大家闺秀, 也有贵族千金。她们除了少数能得到皇帝的宠爱外，大部分没有见过皇帝一面。宫女一 般分成两类: 上层宫女, 主要妃嫔等级的宫女; 下层宫女就是无位号、地位比较卑贱的 宫女。本论文所提出的宫女生活主要是占绝大多数的下层宫女。

\section{内容}

\section{宫女的历史与来源}

宫女的来源隋炀帝时期。《随书》记载, 随炀帝时, 宫女人数有十万之多。到了唐太宗时期, 宫女仍然有数万之多, 而在唐玄宗时期, 宫女的数量曾达到六万之多。杜甫: “先帝待女八千人”, 白居易《长恨歌》中也说 “佳丽三千人”的说法一点都不夸张。

大部分宫女是从民间挑选出来的有的出身于良家、品德素质比较高, 还有是因为自己或家 人犯罪而被没入宫中的, 她们在后宫的地位最低, 承担着后宫的下等劳动, 也有些凭着自己的 手艺在宫中从事缝㧅、刺绣之类的工作。此外, 还有少数宫女是附属国、地方官, 或者公主进 献入宫的, 她们往往具备特殊的才华, 容易受到皇帝的注意而晋升为嫔妃, 但是她们也常是进 献者安插在黄帝身边的奸细。

大多数的宫女是被逼迫进宫的。唐玄宗天宝年间, 就经常派所谓的 “花鸟使” 到全国各地 挑选美女如: 《和李校书新题乐府十二首 -上阳白发人》: “天宝年中花鸟使, 撩花狎鸟含春思。 满怀墨诏求嫔御, 走上高楼半酣醉。醉酣直入卿士家, 闺闱不得偷回避。” 那些怀着圣旨的 “花 鸟使” 狐假虎威, 蛮横凶悍, 他们醉醺醺地闯入卿士之家, 搜寻深闺俊秀, 强迫年轻貌美的女 子入宫。元稹还写出: “良顾妾心死别, 小女呼爷血泪垂。”, 就是说这些容貌出众的村姑少妇, 被生生拉进宫去，从此远离故土、亲人，开始了悲剧的人生。

\section{宫女在宫里的生活}

有一些宫女是色艺俱佳的宫女, 她们的日常生活主要内容就是学习歌舞、乐器以供皇室宴 乐。王建《宫词一百首》之六十五写到 “内人相继报花开, 准拟君王便看来。逢着五弦琴绣袋, 宜春院里按歌回中。” 诗中写的这位宫女很是聪明, 听人讲花开了, 便想到了君王一定会来看 
花, 于是便加紧练习歌曲, 以便获得宠爱。唐代宫女歌唱的好, 则有机会受宠, 并且会很快成 名。

除了歌舞外, 演奏乐器也是宫女们学习一个重要内容。白居易有著名的《立部伎》, “堂 上坐部笙歌清, 堂下立部鼓笛鸣……立部贱, 坐部贵, 坐部退为立部伎, 击鼓吹笙和杂戏。立 部又退何所任, 始就乐悬操雅音。”

宫廷中色艺俱佳的 “毕竟是少数, 绝大多数都是日复一日的从事着一些枯燥乏味的杂役。 这些宫女一旦入宫就必须一辈子伺候皇帝与妃子们, 她们过着幽囚的生活, 不能嫁人、不能与 家人团聚。而皇帝的淫威、后妃的䵇妒使她们随时都有得罪与被害的可能。唐代诗人因为同情 她们所以在他们的笔下写了很多关于底层宫女的生活、命运与痛苦。

王涯《宫词三十首 (存二十七首)》指出, 宫女看到柔嫩的碧柳, 克制攀着的欲望, 因为这里 是皇帝的必经之地：“碧绣帘前柳散垂，守门宫女欲攀时。曾经玉攀从容处，不敢临风折一枝。” 而朱庆馀在《宫词》指出: “寂寂花时闲院门, 美人相并立琼轩。含情欲说宫中事, 鹦武前头不 敢言。” 宫女们面对学舌的鹦武, 想说话但不敢, 怕如果言语不谨慎, 会给自己找来祸端。这些 宫女不如笼中欢呼雀跃的鸟儿, 连说话的自由也被剥夺了。

王建在《宫词》一百首的《旧宫人》描述一个伺候一辈子的老宫女, 还要给小皇帝酒扫宫 殿的情景：先帝旧宫宫女在，乱丝犹挂风凰钗。霓裳法曲浑抛却，独自花间扫玉阶。还有 “舞 来汗湿罗衣彻, 楼上人扶下玉梯” 就是刚跳完舞, 衣服都湿透了, 而楼上那些看表演的人还需 要别人换扶着走下楼。“每夜停灯慰御衣” 就是每天晚上连灯都灭了, 那些宫女还忙着给皇帝尉 梁衣服。甚至有些宫女深夜也不能就寝, 拜候皇帝宣旨: “䟜到玉阶犹带露, 一时宣赐与宫娃” 等侯皇帝恩赐侯，才算了结她们一天的工作，可见的她们的辛苦。

司马札《宫怨》: “柳色参差掩画楼, 晚莺啼送满宫愁。年年花落无人见, 空逐春泉出御沟。” 这首诗, 是想通过宫苑景物和宫中气氛的描写, 暗示出宫女的愁怨。虽然眼前是春光明媚, 但 是宫女觉得宫花的命运与自己很相似：宫花年年自开自落，但是无人观赏，残花悄然地随水逝 去。这些宫女捆锁在宫中消磨了青春。

白居易的《上阳白发人》: “上阳人, 上阳人，红颜暗老白发新。绿衣监使守宫门，一闭上 阳多少春。玄宗末岁初选入, 入时十六今六十。同时采择百余人, 零落年深残此身。忆昔吞悲 别亲族, 扶入车中不教哭。皆云入内便承恩, 脸似芙蓉胸似玉。未容君王得见面, 已被杨妃遥 侧目。妒令潜配上阳宫, 一生遂向空房宿。宿空房, 秋夜长, 夜长无宊天不明。耿耿残灯背壁 影, 萧萧暗雨打窗声。春日迟, 日迟独坐天难暮。宫茑百啭愁厌闻, 梁燕双栖老休妒。莺归燕 去长悄然, 春往秋来不记年。唯向深宫望明月, 东西四五百回圆。今日宫中年最老, 大家遥赐 尚书号。小头鞋履窄衣裳, 青黛点眉眉细长。外人不见见应笑, 天宝末年时世妆。上阳人, 苦 最多。少亦苦, 老亦苦, 少苦老苦两如何? 君不见昔时吕向美人赋, 又不见今日上阳白发歌!” 描写宫女在宫里服务了一辈子 (由 “红颜” 到 “白发”) 而且在宫里经过寂寞、无奈、悲凉的一 生, 入宫时才十六岁, 离别亲友的悲伤, 没见过皇帝一面。“脸似芙蓉胸似玉” 是说少女理应享 受青春和爱情的幸福, 而帝王的生活扼杀了她最宝贵的青春和幸福, 她成了帝王无㙜的牺牲品。 到了垂暮之年，皇帝以 “遥踢尚书号” 的空名愚弄她，人们对她相隔数代的古老妆扮投以冷嘲 的目光, 她集少苦老苦于一身。社会的不公, 人世的不幸, 全重压在她身上。她没有直接对社会 
进行抗争和遗责，但从这痛苦和郁愤的形象中，我们似感到一种巨大而又潜在的反抗力量。

王昌龄《长信秋词》从不同的角度看宫女的生活, 其中四首写的是失宠的一个宫女。她不 理解就是皇帝原本是喜新厌旧的本色所以造成她的悲剧命运, 最后只能觉得自己命不好。虽然 已经失宠，但是还往不了往事，梦见到君王，醒后还怀疑是真的还是幻觉：“真成薄命久寻思， 梦见君王觉后疑。” 正在疑惑不定的时候, 忽然看到辉煌灯火, 照耀西宫, 才意识到君王在西宫 夜饮和别人在一起, 心情无法说出来: “火照西宫知夜饮, 分明复道奉恩时。长信宫中秋月明, 昭阳殿下捣衣声。白露堂中细草迹, 红罗帐里不胜情。”

下层宫女中最惨的要算是守陵宫女。虽然皇帝已经龙驾归天, 在其陵园内, 仍有大批妃嫔 像平日一样侍奉这位死皇帝。韩愈《丰陵行》: “ “设官置卫锁嫔妓, 供养朝夕像平居”, 白居 易《陵园妾》有 “中官监送锁门回”, 说明配置陵园有强迫性质。守陵者中不仅有去世皇帝的 妃嫔宫女，还有在世皇帝的失意或获罪宫嫔。

\section{宫女出宫后的生活}

宫女出宫唐代没有执行过宫女的退休制度, 而是一直执行宫女终身制, 但是据记载, 唐代 有不少释放宫女的记录。放宫女出宫的原因很多, 比如新皇帝即位, 放旧迎新; 如果自然灾害 出现有时候放宫女为了顺应天; 还有一些宫女年老多病; 把宫女当作礼品赏赐给功臣或者得到 皇帝看重的人。《唐会要》记载了唐敬宗长庆四年二月的敕文, 指出年老及残疾的宫女放出宫, 这就是所谓的 “淘汰法则”: “其月敕文: 宫中老年及残疾不任使役, 并有父母者, 并委所司, 选择放出。”

王建的《宫词一百首》之三十七写道: “因吃樱桃病放归, 三年著破旧罗衣。” 这句告诉我 们这位宫女因为生病就被赶出宫。

李白《怨歌行 (长安见内人出嫁, 友人令余代为之)》, 这就是宫女在宫廷争宠斗争中失败, 被赶出宫的例子: “十五入汉宫, 花颜笑春红。君王选玉色, 侍寝金屏中。荐枕娇夕月, 卷衣恋 春风。宁知赵飞燕, 夺宠恨无穷。沉忧能伤人, 绿髸成霜蓬。一朝不得意, 世事徒为空。肃霜 换美酒, 舞衣罢雕龙。寒苦不忍言, 为君奏丝桐。肠断弦亦绝, 悲心夜忡忡。”

吴少微的《相和歌辞・怨歌行》描写一个宫女年轻时凭着歌舞方面才进宫, 并曾经得到皇帝 的宠爱, 但是后来因为皇帝喜新厌旧就失宠了。她在晚年的时候被放出宫。“城南有怨妇, 喊怨 倚兰从。自谓二八时, 歌舞入汉宫, 皇恩弄幸玉堂中。……是时别君不再见, 三十三春长信殿。…… 归来谁为夫, 请谢西家妇, 莫辞先醉解罗襦。”

虽然有些被放出宫的宫女得到了幸福比如据《云溪友议》记述, 宣宗时, 舍人卢渥到长安 应举，偶然来到御沟旁，看见一片红叶，上面题有这首诗： “流水何太急, 深宫尽日闲。殷勤 谢红叶, 好去到人间。”, 就从水中取去, 收藏在巾箱内。后来, 唐宣宗李忱裁减宫女, 准许 宫女嫁百官司吏。他娶了一位被遣出宫的姓韩的宫女。一天, 韩氏见到箱中的这片红叶, 幽幽 地叹息道: “当时偶然题诗叶上, 随水流去, 想不到郎君收藏在此。” 但是唐诗中描写的被放 出宫的宫女多数是那些过去从事歌舞的宫伎, 她们出宫后的命运往往凄凉无奈, 正如徐凝《上 阳红叶》写的 “千声万片御沟上, 一片出宫何处流? ” 
王建《温泉宫行》写道这些流落到民间的宫女们以乐舞技艺谋生: “梨园弟子偷曲谱，头白 人间教歌舞。”

杜牧《出宫人二首》“闲吹玉殿昭华管, 醉折梨园缥蒂花。十年一梦归人世, 㖓缕犹封系臂 纱。平阳拊背穿驰道, 铜雀分香下璧门。几向缀珠深殿里, 妒抛羞态卧黄昏。”

\section{结语}

唐代诗人通过他们写的诗歌, 我们可以看出宫女终身被幽禁在宫中内, 没有自身的 自由, 还有担负繁重的工作, 很多年过去了, 青丝染成了白发, 红颜成了枯萎的花落, 在寂寞和悲凉中耗尽了青春和生命。虽然有些宫女被放出宫而且得到了自己的幸福但是 有很多无家可归, 流落民间, 过着飘零无依的生活。被放出宫的那些宫女一般就是因为 生病或年老，懂一些才艺的只能以乐舞表演来维持她们的生活。

通过这些宫女的生活我们了解了当时其中之一的女性生活, 看清了这些女子的努 力, 四徒生活和万物身份的同时我们也可以看到人们对封建社会的做法感到不满。这些 诗歌展现了文人对于唐代女性的压迫表示同情而且进行控诉。

\section{参考文献}

江建高著. 唐诗散论. 哈尔滨：黑龙江人民出版社： 2006 年 01 月第 1 版

刘洁著. 唐诗审美十论. 北京：民族出版社，2002.03

姜维公 姜维东. 唐代宫女生活述略. 社会科学战线, 2010 年第三期 - 唐宋史研究

苏者聪. 论唐代宫女诗及宫女命运. 武汉大学学报（社会科学版），1986 年第五期

全唐诗. http://www. xysa. com/quantangshi/s-521. htm 